\title{
Zahnärzte favorisieren die Übernahme einer Einzelpraxis
}

\author{
Unter Zahnärzten ist die Einzelpraxis die beliebteste Niederlassungsform. Das zeigt der aktuelle \\ InvestMonitor Zahnarztpraxis vom Institut der Deutschen Zahnärzte (IDZ) und der Deutschen \\ Apotheker- und Ärztebank (apoBank). Datengrundlage sind 440 von der apoBank durchgeführte \\ Finanzierungen zahnärztlicher Existenzgründungen im Jahr 2015.
}

Demnach stieg der Anteil der übernommenen Einzelpraxen zwischen 2011 und 2015 von 57 auf 65 Prozent. Der Trend zur Einzelpraxisübernahme als am meisten verbreitete Niederlassungsform setzte sich der Studie zufolge in allen Altergruppen durch. Im Vergleich dazu entschieden sich rund 28 Prozent für die Niederlassung in Form einer Berufsausübungsgemeinschaft (BAG). Lediglich sieben Prozent gründeten allein eine neue Praxis. Hierbei fielen die höchsten Investitionen an (421.000 Euro). Weniger mussten die Zahnärzte bei Übernahme einer Einzelpraxis (273.000 Euro) oder einer BAG (250.000 Euro) aufwenden. Das Gesamtfinanzierungsvolumen fällt bei allen Niederlassungsformen etwas höher aus, weil zusätzlich der Betriebsmittelkredit berücksichtigt wird.

\section{Große Spanne bei Übernahmepreisen}

Deutliche Preisunterschiede gibt es nach Angaben der apoBank bei der Übernahme einer Praxis. Während etwa 14 Prozent der Übernehmer rund 50.000 Euro oder weniger zahlten, gaben etwa acht Prozent der Existenzgründer sogar 350.000 Euro aus. Diese Bandbreite entstehe durch den unterschiedlichen materiellen Wert, wie etwa der Praxisausstattung, und dem ideellen Wert, dazu zählen unter anderem die aktuelle wirtschaftliche Situation, der Patientenstamm und das zukünftige Potenzial der Praxis.

Weiterhin zeigt die Altersstruktur, dass sich zwei Drittel der Zahnärzte zwischen dem 31. und 40. Lebensjahr niederlassen. Dabei ist es auffallend, dass die jüngeren Existenzgründer bis 30 Jahre tendenziell eher kooperieren (39 Prozent) als die Gründer über 40 Jahre (22 Prozent). Zudem geht aus der Studie her- vor, dass das Durchschnittsalter bei erstmaliger Niederlassung zwischen den Geschlechtern variiert. Die männlichen Existenzgründer waren im Schnitt 35,1 Jahre alt, Frauen 36,3 Jahre. Bei der präferierten Niederlassungsform konnte die Studie insgesamt keine geschlechterspezifischen Unterschiede ermitteln. Hier steht die Übernahme der Einzelpraxis weiterhin bei Zahnärzten und Zahnärztinnen hoch im Kurs.

\section{Zahnarztdichte nimmt in Großstädten zu}

Das bekannte Stadt-Land-Gefälle zeigt die Studie auch für die Zahnärzteschaft. Zwar steigt der Anteil der Existenzgründungen in ländlichen Gebieten seit 2011 stetig (plus sechs Prozentpunkte), aber gemessen an der Bevölkerungszahl sind Zahnärzte im ländlichen Raum weiterhin unterrepräsentiert. In den Großstädten nahm der Anteil der zahnärztlichen Existenzgründungen um zehn Prozentpunkte ab. Dennoch kommt der InvestMonitor zu dem Ergebnis, dass sich Zahnärzte, verglichen mit der Bevölkerungszahl, überproportional häufig in großstädtischen Lagen niederlassen. Mit Blick auf die Zahnarztdichte und die neuesten Zahlen der Existenzgründungskosten forderte der Vorstandsvorsitzende der Kassenzahnärztlichen Bundesvereinigung, Dr. Wolfgang Eßer, sichere und attraktive Rahmenbedingungen für die zahnärztliche Berufsausübung. „Nur so kann die Hemmschwelle für die Niederlassung in eigener Praxis abgebaut werden. Es sind die kleineren Praxen, die den größten Beitrag dazu leisten, dass es im zahnärztlichen Bereich keine Unterversorgung auf dem Land und keine Wartezeiten in Praxen gibt.“

Carolin Stehr

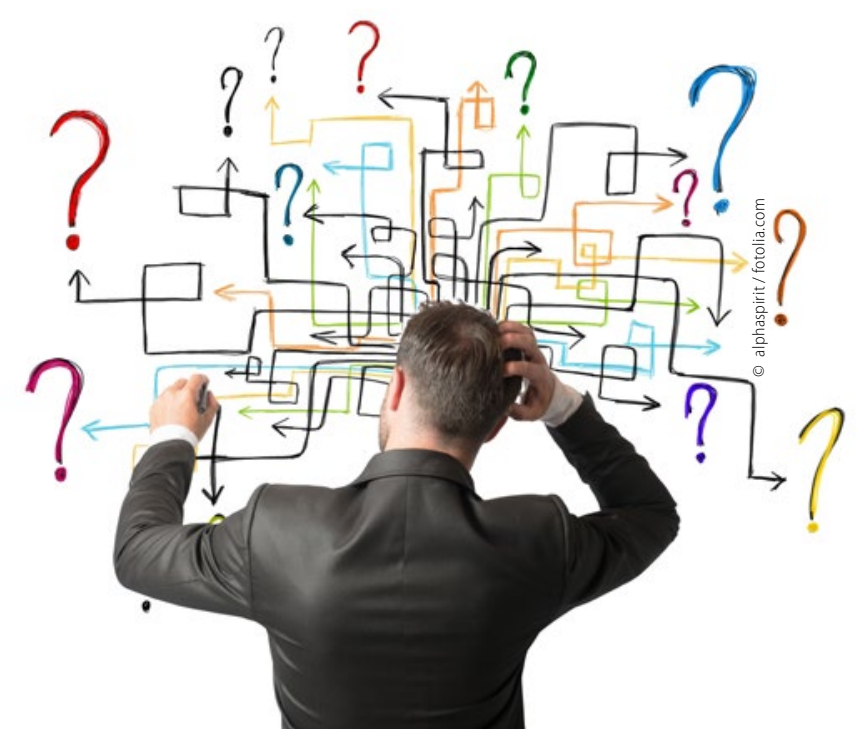

